\title{
Clinical utility of fixed combinations of sitagliptin-metformin in treatment of type 2 diabetes
}

This article was published in the following Dove Press journal: Diabetes, Metabolic Syndrome and Obesity:Targets and Therapy 22 October 2010

Number of times this article has been viewed

\author{
Karen Barnard ${ }^{1,2}$ \\ Mary Elizabeth Cox' \\ Jennifer B Green ${ }^{1,2}$ \\ 'Department of Medicine, Division of \\ Endocrinology, Diabetes, Metabolism \\ and Nutrition, Duke University \\ Medical Center, Durham, NC, USA; \\ ${ }^{2}$ Department of Medicine, Division \\ of Endocrinology, Durham Veterans \\ Affairs Medical Center, Durham, NC, \\ USA
}

Correspondence: Karen Barnard Department of Medicine, Division of Endocrinology, Durham Veterans Affairs Medical Center, Room A8002/I I IC, 508 Fulton Street, Durham, NC 27705, USA $\mathrm{Tel}+|9| 928604||$

Fax +19192866873

Email karen.barnard@duke.edu

\begin{abstract}
Adequate glycemic control in type 2 diabetes remains a difficult but achievable goal. The development of new classes of glucose-lowering medications, including in particular the incretin-based therapies, provides an opportunity to utilize combinations of medications which target multiple physiologic abnormalities in type 2 diabetes. Complementary combination therapy with sitagliptin-metformin lowers glucose via enhancement of insulin secretion, suppression of glucagon secretion, and insulin sensitization. Use of this combination in diabetes management will provide a greater degree of glycosylated hemoglobin-lowering than that seen with the use of either drug as monotherapy, is unlikely to cause significant hypoglycemia, and is generally associated with weight loss. The effectiveness, tolerability, and potential cost savings associated with the use of sitagliptin-metformin combination therapy make this an attractive option in diabetes management. The possible beneficial effects of this therapy on beta cell function, as well as its cardiovascular impact, remain inadequately explored but are of significant interest.
\end{abstract}

Keywords: diabetes mellitus, sitagliptin, dipeptidyl peptidase-4, combination therapy

\section{Current perspective on treatment of type 2 diabetes}

Because the number of individuals affected by diabetes is continuing to increase worldwide, the need for effective management assumes ever greater urgency. In 2007 , it was estimated that $7.8 \%$ of the US population was affected by diabetes, with the global number of affected individuals likely to exceed 220 million. ${ }^{1,2}$ Although glycemic control has been shown to minimize the development and progression of diabetes-related complications, it remains elusive for many. ${ }^{3}$ The National Health and Nutrition Examination Survey 2003-2004 found that only 57.1\% of patients with diabetes had a glycosylated hemoglobin $\left(\mathrm{HbA}_{1 \mathrm{C}}\right)$ level below the current treatment target of $7.0 \% .{ }^{4}$ Despite the improvement from $35.8 \%$ at $\mathrm{HbA}_{1 \mathrm{C}}$ goal in the $1999-2000$ survey, almost half of individuals with type 2 diabetes remain suboptimally managed. The challenges encountered in the achievement and maintenance of adequate glycemia are many, due in large part to the complex pathophysiology which contributes to the development of type 2 diabetes. Metabolic abnormalities including insulin resistance, at least relative insulin deficiency, and glucagon excess must be considered when prescribing effective glucose-lowering therapies.

Recommendations regarding the institution and intensification of antihyperglycemic therapy have become more aggressive in recent years. Reliance on lifestyle modification alone has been discouraged, because this approach has not been found likely to accomplish either adequate or durable glycemic control for most. ${ }^{5}$ 
Initiation of glucose-lowering medication at the time of diabetes diagnosis, generally in the form of metformin, has been suggested. ${ }^{5}$ Although this may improve glycemic control early on in the course of the condition, many traditionally used glucose-lowering medications (including metformin) have not been found to alter substantially the progressive deterioration in beta cell function and glycemia that occurs in type 2 diabetes. ${ }^{6}$ Nonadherence to prescribed therapies, often due to cost, inconvenience, medication side effects, and/or regimen complexity, may also present a challenge to glycemic control. Furthermore, diabetes care providers may fail to implement effective therapies due simply to clinical inertia or perhaps a poor understanding of the expected potency or durability of the glucose-lowering therapies that they prescribe.

On a more positive note, the variety of antihyperglycemic medications now available may permit greater individualization of therapy, and perhaps more successful therapy, than had previously been possible. Newer classes of medications, particularly those which work via the incretin pathway, achieve glucose lowering without the risk of weight gain or hypoglycemia conveyed by more traditional therapies, such as insulin or sulfonylureas. Because many agents with differing mechanisms of action are now available, complementary combinations of these medications may permit glucose lowering in an effective and well tolerated fashion. Several studies have demonstrated that combinations of different classes of oral agents are more effective in glucose lowering than are maximal doses of a single drug, leading to recommendations by many authors that combination therapies be considered early or initially in the management of type 2 diabetes. ${ }^{7-10}$ For example, the American Association of Clinical Endocrinologists suggests initial combination therapy for patients with an $\mathrm{HbA}_{1 \mathrm{C}}$ in the range of $7 \%-8 \%$ at the time of diabetes diagnosis. ${ }^{11}$ In addition to targeting multiple metabolic abnormalities underlying type 2 diabetes, combination therapies may result in improved adherence due to the smaller number of pills needed to be taken daily, and in some cases a reduction in overall medication costs. Furthermore, combinations of less than maximal doses of medications may permit effective glucose lowering with a minimization of the side effects associated with each individual drug class. Ideally, combination therapies should be well tolerated, convenient to take, have few contraindications, have a low risk of hypoglycemia and weight gain, and be reasonably effective over both the short and long term. This article will review the available data regarding the effectiveness, safety, and utility of fixed combinations of metformin and the dipeptidyl peptidase-4 (DPP-4) inhibitor sitagliptin in the treatment of type 2 diabetes.

\section{Mechanisms of action and pharmacology Sitagliptin}

Sitagliptin is an orally administered agent which exerts its glucose-lowering effects via inhibition of the activity of the DPP-4 enzyme. This enzyme, in addition to circulating in a soluble form in plasma, is expressed in a variety of tissues including the liver, kidney, lung, and lymphocytes. ${ }^{12}$ DPP-4 is responsible for the rapid degradation of the incretin hormones, glucagon-like peptide-1 (GLP-1) and glucosedependent insulinotropic peptide (GIP), which are released from the gut in response to food intake. The active intact forms of GLP-1 and GIP both stimulate insulin secretion in a glucose-dependent fashion; additionally, GLP-1 contributes to glucose homeostasis via regulation of gastric emptying and glucose-dependent suppression of glucagon secretion. ${ }^{13}$ Individuals with type 2 diabetes are deficient in GLP-1 and have diminished responsiveness to GIP. ${ }^{13-15}$ Sitagliptin therapy in individuals with type 2 diabetes increases levels of and prolongs the half-lives of the active intact incretin hormones; these, in turn, lower glucose via enhancement of the insulin response to glucose and a decrease in glucagon secretion. ${ }^{16}$ The likelihood of hypoglycemia due to DPP-4 inhibitor monotherapy is low because the incretin hormones do not exert glucose-lowering effects when glucose levels are below normal.

Sitagliptin is available in an oral tablet which may be administered with or without food. It is highly selective for DPP-4, with significantly greater affinity for that enzyme than for the related enzymes DPP-8 and DPP-9. ${ }^{17}$ Administration of sitagliptin rapidly inhibits the activity of DPP-4 in a dose-dependent fashion. Doses of $50 \mathrm{mg}$ and $100 \mathrm{mg}$ inhibit the activity of the enzyme by $80 \%$ over 12 and 24 hours, respectively. This degree of inhibition yields a two- to three-fold increase in active GLP-1 levels, and is the level of inhibition at which near maximal glucose lowering is seen. In individuals with type 2 diabetes, sitagliptin therapy exerts its glucose-lowering effects via increased insulin secretion and suppression of glucagon release. The majority of the administered drug is excreted unchanged in the urine via active tubular secretion. ${ }^{17,18}$ Sitagliptin is minimally metabolized prior to excretion and does not appear to inhibit or induce cytochrome P450 enzymes, making the potential for adverse interactions with other medications low. No significant alterations in the pharmacokinetics of rosiglitazone, glyburide, 
or metformin are known to occur following sitagliptin administration. ${ }^{16,18}$ The usual recommended daily dose of sitagliptin is $100 \mathrm{mg}$; however, because renal insufficiency increases drug exposure, the dose should be reduced in individuals with modest or severe renal dysfunction. The recommended daily dose is $50 \mathrm{mg}$ for patients with a creatinine clearance $30-50 \mathrm{~mL} / \mathrm{min}$ and $25 \mathrm{mg}$ daily for patients with a creatinine clearance $<30 \mathrm{~mL} / \mathrm{min}$. Renal function should be monitored periodically in patients using sitagliptin in order to ensure appropriate medication dosing. ${ }^{19}$

\section{Metformin}

Metformin, an inexpensive oral antihyperglycemic agent, exerts its glucose-lowering effects primarily through increased hepatic insulin sensitivity and the resultant suppression of hepatic glucose output. ${ }^{20}$ Metformin may also modestly enhance glucose uptake in peripheral tissues and increase glucose metabolism in the splanchnic bed. ${ }^{21}$ Interestingly, administration of metformin to obese subjects has been found to increase levels of active GLP-1 via mechanisms other than DPP-4 inhibition. Direct stimulation of GLP-1 secretion, or perhaps a reduction in DPP-4 secretion, is thought to be responsible for this phenomenon. ${ }^{22,23}$ Because metformin does not exert its effects through a direct increase in insulin secretion, the likelihood of hypoglycemia induced by metformin monotherapy is also quite low.

Metformin is $50 \%-60 \%$ orally bioavailable. Administration with food may decrease absorption, although the clinical significance of this is unknown. It is minimally protein-bound, and has few drug interactions other than that seen with coadministration of cimetidine, which increases metformin levels by up to $40 \%$. The drug has an elimination half-life of approximately six hours, and is generally dosed 2-3 times daily. However, an extended-release preparation is available which may be administered once a day. A daily dose of $500 \mathrm{mg}$ three times daily will exert $85 \%$ of the maximal glucose-lowering effect, but doses up to $2000 \mathrm{mg}$ daily may be prescribed. ${ }^{21,24}$ Metformin is not metabolized prior to its complete excretion in the urine, thus decreases in renal function will reduce clearance of the medication. Metformin accumulation has been associated with lactic acidosis. Although this complication is uncommon, the condition is fatal $50 \%$ of the time. ${ }^{25}$

\section{Rationale for use of a sitagliptin-metformin combination}

As outlined in the preceding sections, the differing mechanisms of action of sitagliptin and metformin would be expected to have additive effects upon glucose lowering in type 2 diabetes. The three main defects in diabetes, which include impaired insulin secretion, insulin resistance, and glucagon excess, will all be targeted by such a combination of medications. Although both metformin and sitagliptin monotherapy have been found to increase GLP-1 levels, this appears to occur through different physiologic pathways. Indeed, coadministration of sitagliptin-metformin to individuals with type 2 diabetes has been found to result in GLP-1 elevation in excess of that seen with administration of either drug alone. ${ }^{27}$ The complementary mechanisms of action, lack of adverse pharmacologic interactions, and limited potential for hypoglycemia associated with the two medications make this an attractive therapeutic combination. Fixed combination tablets are available in doses of $50 \mathrm{mg}$ sitagliptin $+500 \mathrm{mg}$ metformin or $50 \mathrm{mg}$ sitagliptin $+1000 \mathrm{mg}$ metformin. ${ }^{19}$

\section{Efficacy of sitagliptin-metformin combination therapy}

Data from published trials evaluating the efficacy of sitagliptin-metformin combination therapy are summarized in Table 1. Results from eight large, randomized, pharmaceutical industry-sponsored trials have been published since 2006. Four of these trials utilized placebo controls, while four included therapy with an active comparator.

Charbonnel et al performed a multinational, double-blind, parallel-group study that enrolled 701 predominantly white male subjects, with a mean age of 54 years and a mean baseline $\mathrm{HbA}_{1 \mathrm{C}}$ of $8.0 \%$ on metformin alone at a minimum dose of $1500 \mathrm{mg}$ daily. ${ }^{28}$ Subjects were randomly assigned to additional therapy with either placebo or sitagliptin $100 \mathrm{mg}$ daily. At 24 weeks, sitagliptin-metformin therapy resulted in a placebo-subtracted $\mathrm{HbA}_{1 \mathrm{C}}$ reduction of $0.65 \%$. Combination therapy resulted in significantly more subjects achieving an $\mathrm{HbA}_{1 \mathrm{C}}$ of less than $7 \%$ when compared with metformin monotherapy, and significantly lowered fasting plasma glucose. Sitagliptin-metformin combination therapy was associated with greater increases in C-peptide and homeostasis model assessment of beta cell function (HOMA $\beta$ ) than seen with metformin therapy alone, suggestive of enhancement in beta cell function. Furthermore, a reduction in the proinsulin/insulin ratio seen only in the combination therapy group may represent an improvement in insulin processing conveyed by this treatment. Mean body weight decreased significantly from baseline in both treatment groups ( -0.6 to $-0.7 \mathrm{~kg}$ ) without any significant between-group differences. Rates of discontinuation and the incidence of adverse drug-related events (including hypoglycemia and gastrointestinal side effects) were similar in the two groups. 


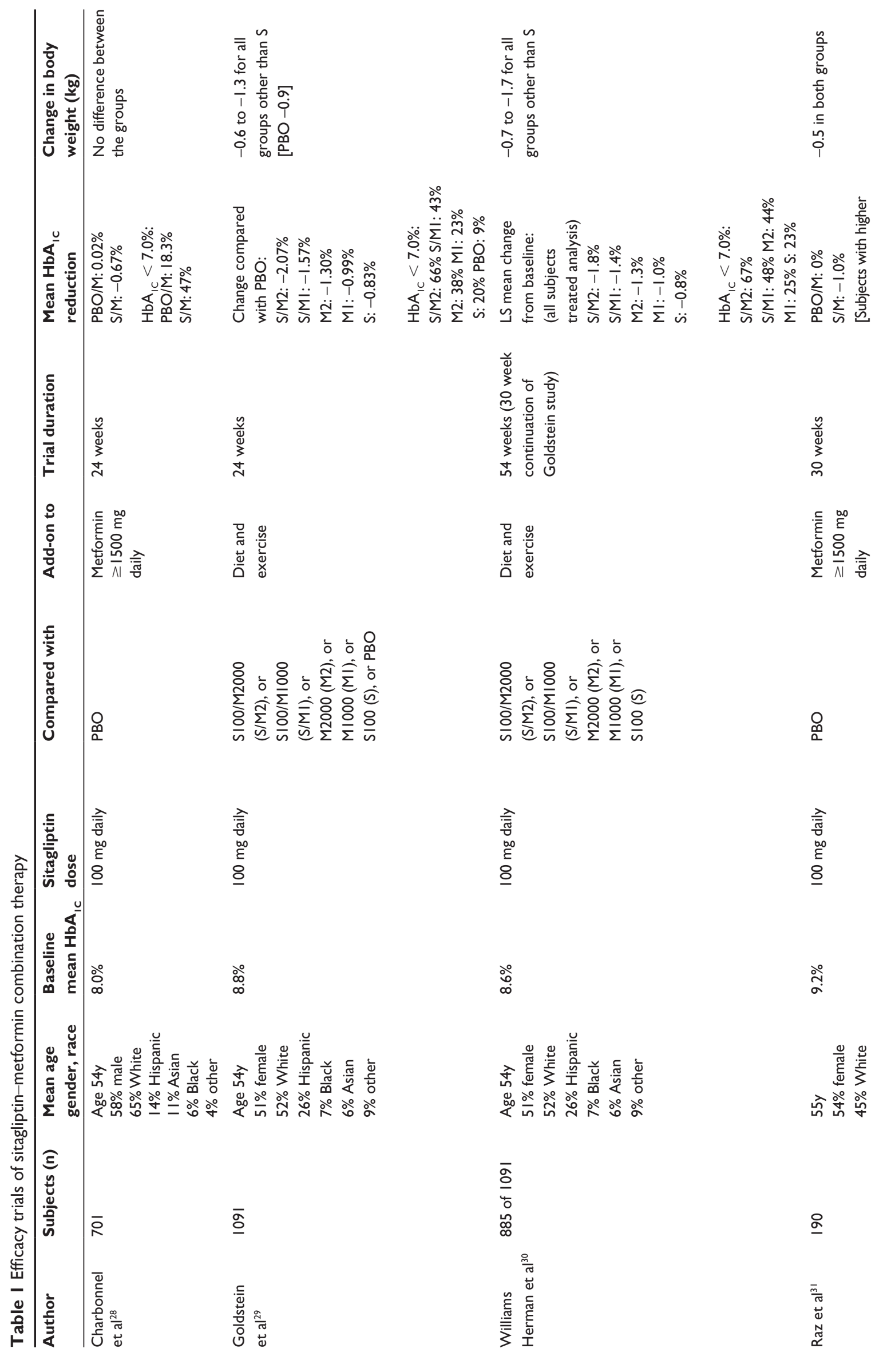




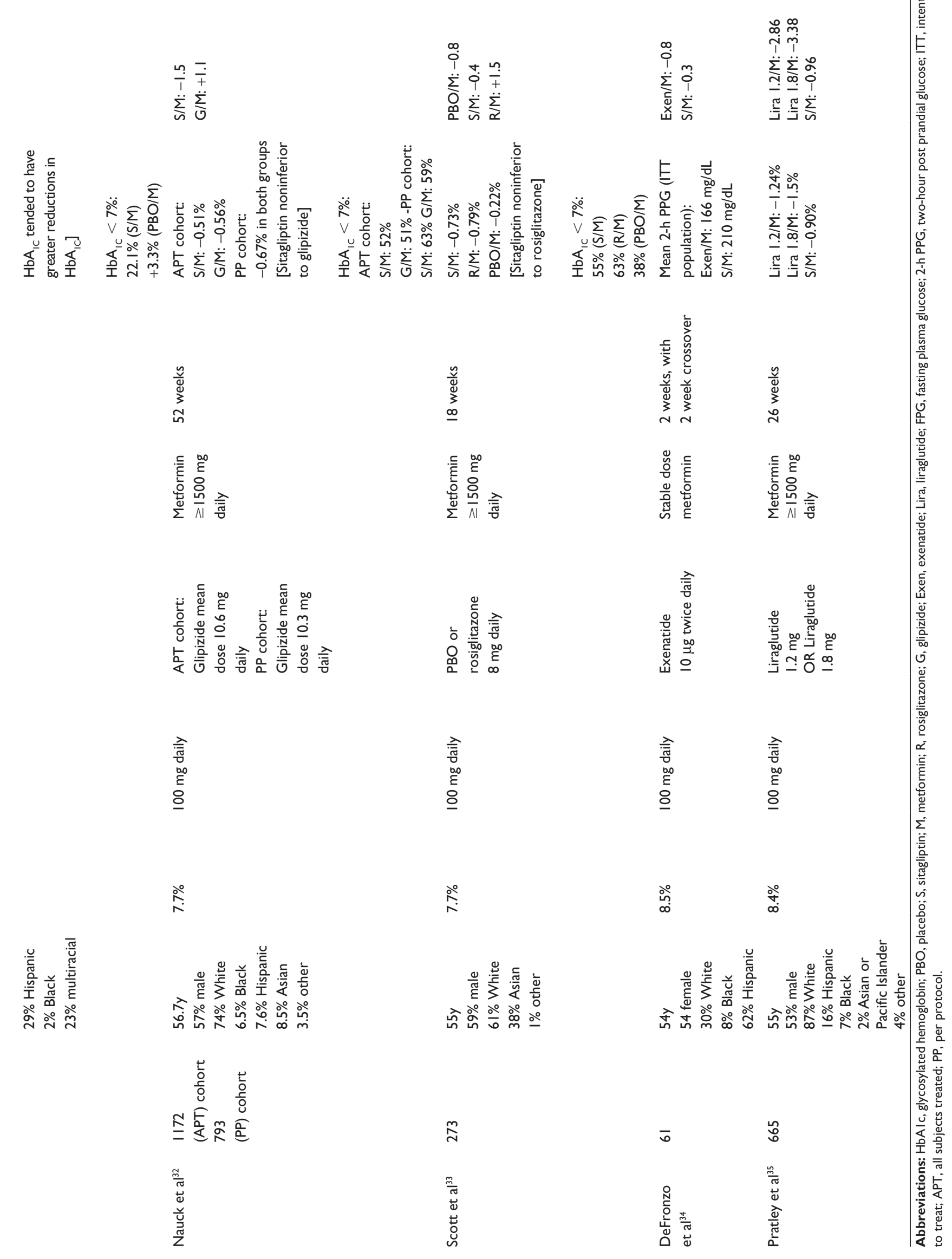


In another large placebo-controlled multinational trial, Goldstein et al randomized 1091 men and women with a mean baseline $\mathrm{HbA}_{1 \mathrm{C}}$ of $8.8 \%$ to one of six daily treatments, ie, sitagliptin $100 \mathrm{mg}+$ metformin $2000 \mathrm{mg}$, sitagliptin $100 \mathrm{mg}+$ metformin $1000 \mathrm{mg}$, metformin $2000 \mathrm{mg}$, metformin $1000 \mathrm{mg}$ (all dosed in evenly divided, twice-daily doses), sitagliptin $100 \mathrm{mg}$, or placebo. ${ }^{29}$ At 24 weeks, when compared with placebo, the active treatments significantly reduced $\mathrm{HbA}_{1 \mathrm{C}}$ by $2.07 \%, 1.57 \%, 1.30 \%, 0.99 \%$, and $0.83 \%$, respectively. The proportion of subjects achieving an $\mathrm{HbA}_{1 \mathrm{C}}<7 \%$ was significantly higher in the sitagliptin $100 \mathrm{mg}+$ metformin $2000 \mathrm{mg}$ group than in the sitagliptin $100 \mathrm{mg}+$ metformin $1000 \mathrm{mg}$ group. In an open-label, high$\mathrm{HbA}_{1 \mathrm{C}}$ cohort, a group of patients with mean baseline $\mathrm{HbA}_{1 \mathrm{C}}$ $11.2 \%$ treated with sitagliptin $100 \mathrm{mg}+$ metformin $2000 \mathrm{mg}$ achieved a mean $\mathrm{HbA}_{1 \mathrm{C}}$ lowering of $2.9 \%$. With the exception of sitagliptin monotherapy, which resulted in no significant change in body weight, all active treatment groups experienced significant reductions in body weight relative to baseline $(-0.6$ to $-1.3 \mathrm{~kg} ; P<0.005)$. The incidence of hypoglycemia and gastrointestinal side effects were similar for all active therapies. After the main trial was completed, 885 of 1091 subjects entered a 30-week continuation trial and remained on their previously assigned active oral treatments. ${ }^{30}$ Those in the placebo group were switched to metformin $2000 \mathrm{mg}$ daily (results from this switch group were excluded from the final analysis). Glycemic response was durable over time across the active treatment groups. In the all-patients-treated analysis at week 54, the mean $\mathrm{HbA}_{1 \mathrm{C}}$ reductions from baseline were: sitagliptin $100 \mathrm{mg}+$ metformin $2000 \mathrm{mg}, 1.8 \%$; sitagliptin $100 \mathrm{mg}$ + metformin $1000 \mathrm{mg}, 1.4 \%$; metformin $2000 \mathrm{mg}, 1.3 \%$; metformin $1000 \mathrm{mg}, 1.0 \%$; and sitagliptin $100 \mathrm{mg}, 0.8 \%$. The proportion of subjects with $\mathrm{HbA}_{1 \mathrm{C}}<7 \%$ in the above groups were $67 \%, 48 \%, 44 \%, 25 \%$, and $23 \%$, respectively. Mean decrease in weight from baseline was 0.7 to $1.7 \mathrm{~kg}$ in all groups other than the sitagliptin monotherapy group, in which mean weight did not change significantly. As in the initial trial, the incidence of hypoglycemia and gastrointestinal side effects was similar among the groups.

In a third multinational, placebo-controlled trial, Raz et al randomly assigned 190 men and women (mean age 55 years, mean $\mathrm{HbA}_{1 \mathrm{C}} 9.2 \%$ ) on a stable dose of $\geq 1500 \mathrm{mg}$ metformin daily to the addition of either placebo or sitagliptin $100 \mathrm{mg}$ daily. ${ }^{31}$ At 30 weeks, the sitagliptin-metformin group achieved a $1.0 \%$ placebo-subtracted $\mathrm{HbA}_{1 \mathrm{C}}$ reduction. Weight decreased by $0.5 \mathrm{~kg}$ in both groups. Study discontinuation and clinical adverse events (including hypoglycemia and gastrointestinal side effects) were similar in the two groups.
While the percentage of subjects with laboratory adverse events was higher in the sitagliptin-metformin group (15\%) compared with the placebo-metformin group (4.3\%), the only discernible pattern was a decrease in hemoglobin which occurred in subjects with illnesses that predisposed to blood loss. None of the laboratory adverse events were considered serious or drug-related.

There have been four randomized trials comparing sitagliptin-metformin with active comparators, including the additions of glipizide, rosiglitazone, exenatide, or liraglutide to baseline metformin therapy. First, in a 52-week multinational, double-blind, noninferiority trial, 1172 men and women (mean age 57 years, mean $\mathrm{HbA}_{1 \mathrm{C}}$ 7.7\%) receiving metformin $\geq 1500 \mathrm{mg}$ daily were randomized in a $1: 1$ ratio to the addition of sitagliptin $100 \mathrm{mg}$ daily or glipizide (mean within-trial dose $10.5 \mathrm{mg}$ daily) ${ }^{32}$ In the per protocol analysis, both groups experienced a mean $\mathrm{HbA}_{1 \mathrm{C}}$ lowering of $0.67 \%$. $\mathrm{HbA}_{1 \mathrm{C}}$ lowering to $<7 \%$ occurred in $63 \%$ of subjects in the sitagliptin-metformin group and in 59\% in the glipizide-metformin group. The sitagliptin-metformin group had a significant mean weight change of $-1.5 \mathrm{~kg}$, while a weight gain of $1.1 \mathrm{~kg}$ was experienced by the glipizide-metformin group. The proportion of subjects experiencing hypoglycemia was significantly higher in the glipizide-metformin group than in the sitagliptin-metformin group (32\% and 5\%, respectively). Notably, 202 subjects in the sitagliptin-metformin group discontinued treatment due to "lack of efficacy", compared with 172 in the glipizidemetformin group. Those subjects who discontinued due to lack of efficacy had a higher mean $\mathrm{HbA}_{1 \mathrm{C}}$ at baseline than did those who completed the study (8.6\% versus $7.5 \%)$.

A second active comparator trial was performed by Scott et al who examined 273 subjects (60\% white and male, mean age 55 years, mean $\mathrm{HbA}_{1 \mathrm{C}} 7.7 \%$ ) on metformin therapy ( $\geq 1500 \mathrm{mg}$ daily), randomizing them to the addition of either placebo, sitagliptin $100 \mathrm{mg}$ daily, or rosiglitazone $8 \mathrm{mg}$ daily. ${ }^{33}$ At 18 weeks, both active treatment groups had significant decreases in $\mathrm{HbA}_{1 \mathrm{C}}$ from baseline; $-0.51 \%$ and $-0.57 \%$ in the sitagliptin-metformin and rosiglitazone-metformin groups, respectively. The proportion of patients experiencing $\mathrm{A}_{1 \mathrm{C}}$ lowering to $<7 \%$ was greater in the sitagliptin-metformin $(55 \%)$ and rosiglitazone-metformin $(63 \%)$ groups when compared with placebo-metformin (38\%). Mean weight increased in the rosiglitazone-metformin group by $1.5 \mathrm{~kg}$, whereas those treated in the sitagliptin-metformin and placebo-metformin groups lost weight $(-0.4 \mathrm{~kg}$ and $-0.8 \mathrm{~kg}$, respectively). Both active drugs were well tolerated with no difference in the incidence of hypoglycemia or gastrointestinal 
adverse effects. The proportions of subjects who discontinued the study were higher in the sitagliptin-metformin and placebo-metformin groups (10\% and 9\%, respectively) when compared with the rosiglitazone-metformin group (2\%). Adverse experiences (3\%) and withdrawal of consent (4\%) were the most common reasons cited for discontinuation in the sitagliptin-metformin group.

In a multicenter, randomized, double-dummy, crossover Phase IV trial in 61 men and women (mean age 54 years, mean $\mathrm{HbA}_{1 \mathrm{C}} 8.5 \%$ ), DeFronzo et al compared sitagliptin-metformin with exenatide-metformin. ${ }^{34}$ Subjects who were on a stable dose of metformin were randomized to either exenatide or sitagliptin for two weeks and crossed over to the alternative therapy for another two weeks. The primary outcome was two-hour postprandial glucose. Exenatide-metformin lowered two-hour postprandial glucose to $166 \mathrm{mg} / \mathrm{dL}$ compared with $210 \mathrm{mg} / \mathrm{dL}$ in the sitagliptin-metformin group. This difference followed the drug after crossover. Exenatide-metformin resulted in greater mean weight loss $(-0.8 \mathrm{~kg})$ than did sitagliptin-metformin $(-0.3 \mathrm{~kg})$. Caloric intake (assessed in 25 subjects) decreased significantly with exenatidemetformin therapy as compared with sitagliptin-metformin, with mean changes from baseline of -134 and $+130 \mathrm{kcal} / \mathrm{day}$, respectively. Gastrointestinal side effects of mild to moderate severity were experienced in both the exenatide-metformin and sitagliptin-metformin groups.

Pratley et al performed a parallel-group, open-label trial in Europe, the US, and Canada to assess the efficacy and safety of the addition of either liraglutide or sitagliptin to metformin therapy ${ }^{35}$ In total, 665 men and women, with a mean age of 55 years and a mean $\mathrm{HbA}_{1 \mathrm{C}}$ of $8.5 \%$, were randomized to receive one of two doses of liraglutide $(1.2 \mathrm{mg}$ or $1.8 \mathrm{mg}$ subcutaneously daily) or sitagliptin $100 \mathrm{mg}$ daily for 26 weeks. Subjects treated with either $1.2 \mathrm{mg}$ or $1.8 \mathrm{mg}$ of liraglutide experienced significantly greater $\mathrm{HbA}_{1 \mathrm{C}}$ lowering compared with sitagliptin (mean $\mathrm{HbA}_{1 \mathrm{C}}$ decreases of $1.24 \%, 1.5 \%$, and $0.9 \%$, respectively). Mean waist circumference decreased by $2.69 \mathrm{~cm}, 2.63 \mathrm{~cm}$, and $1.12 \mathrm{~cm}$ in those receiving liraglutide $1.8 \mathrm{mg}+$ metformin, liraglutide $1.2 \mathrm{mg}+$ metformin, and sitagliptin-metformin, respectively. All subjects experienced weight loss, with mean decreases of $2.86 \mathrm{~kg}, 3.38 \mathrm{~kg}$, and $0.96 \mathrm{~kg}$, reported in the three respective groups.

\section{Nonglycemic effects}

Each trial discussed earlier examined markers of insulin resistance, such as the quantitative insulin sensitivity check index or homeostasis model assessment of insulin resistance (HOMA-IR), as well as HOMA- $\beta$ or other markers of beta cell function. In general, sitagliptin-metformin therapy improved measures of beta cell function to a greater degree than did metformin alone, whereas administration of exenatide or liraglutide tended to outperform sitagliptin on similar measures. No significant changes in estimates of insulin resistance or insulin sensitivity were associated with sitagliptin exposure..$^{28-35}$

\section{Safety and tolerability}

Overall, drugs in the DPP-4 inhibitor class, and sitagliptin specifically, are well tolerated. There is little independent causation of hypoglycemia; however, hypoglycemia may occur when sitagliptin is combined with medications, such as sulfonylureas or insulin. ${ }^{36,37}$ Sitagliptin is generally considered weight-neutral, but the combination of sitagliptin and a sulfonylurea may promote weight gain. Sitagliptin does not appear to attenuate the weight loss effects associated with metformin therapy significantly. There does appear to be a slightly increased risk for nasopharyngitis and headache associated with sitagliptin use. However, in clinical trials, these side effects were unlikely to be severe or result in discontinuation of the medication. ${ }^{37}$

Hypersensitivity events temporally related to initiation of sitagliptin, including anaphylaxis, angioedema, and exfoliative skin conditions, have occurred in the postmarketing period. Continued use of or re-exposure to sitagliptin is contraindicated in patients who have experienced these hypersensitivity reactions. ${ }^{38}$ Additionally, there have been postmarketing reports of pancreatitis occurring in patients treated with sitagliptin, as well as in patients using the GLP-1 analog, exenatide. A subsequently published retrospective review of hospital records did not reveal an increased risk of hospitalization for pancreatitis in patients using sitagliptin or exenatide compared with those using metformin or glipizide for diabetes therapy. ${ }^{39}$ Further study is needed to clarify whether the incretin-related diabetes medications are truly causative, or if these cases might simply be due to use of the medications in a population which is already at greater than average risk for pancreatitis. The US Food and Drug Administration recommends that physicians warn patients about the potential risk as well as the symptoms of pancreatitis, and that sitagliptin be discontinued if symptoms or signs of pancreatitis develop. ${ }^{19}$

The most common adverse effects of metformin are nausea, vomiting, flatulence, and diarrhea, which can occur in up to $20 \%$ of patients. ${ }^{40}$ As previously noted, metformin-associated lactic acidosis may rarely occur, generally reported as approximately 0.03 cases per 1000 patient-years. ${ }^{19}$ The true 
incidence of metformin-associated lactic acidosis is unclear. One recent systematic review, encompassing nearly 50,000 patient-years of use in 206 clinical trials, found no cases of either fatal or nonfatal lactic acidosis to have occurred in conjunction with metformin use. ${ }^{25}$ Still, metformin use is contraindicated in the setting of renal dysfunction (males with a creatinine $\geq 1.5$ and females with a creatinine $\geq 1.4$ ), or in those at risk for lactic acidosis due to hypoperfusion of renal or other tissues. Individuals with acute or chronic metabolic acidosis, significant hepatic dysfunction, or acute or unstable congestive heart failure are not considered candidates for metformin use. The drug should be temporarily discontinued prior to surgery or intravenous contrast administration, and is not recommended for use in individuals aged older than 80 years who do not have a normal creatinine clearance. ${ }^{21,24}$ Some authors have suggested that lower doses of metformin may be safely used in individuals with compromised renal function, but this has not been met with widespread acceptance. $^{26}$

The most common adverse reactions in patients taking both sitagliptin and metformin were diarrhea, upper respiratory tract infection, and headache. ${ }^{19}$ Contraindications to the use of sitagliptin-metformin include the contraindications listed for both of the individual medications. Of note, the precautions regarding metformin use in patients with renal dysfunction also apply to combination therapy. Sitagliptin-metformin combination therapy has not been studied in women who are pregnant or lactating, or in pediatric populations, thus its use cannot be recommended for these patients. Finally, there have been no clinical studies establishing conclusive evidence of macrovascular risk reduction with the use of sitagliptin-metformin or any other antidiabetic drugs. ${ }^{19}$

\section{Quality of life, satisfaction, and acceptability}

Combining sitagliptin and metformin in a single pill has the potential to simplify a patient's treatment regimen. Taken twice daily, this therapy does not have the discomfort or inconvenience associated with multiple daily insulin injections. Furthermore, adherence and patient satisfaction may increase with a regimen which includes a limited number of tablets taken daily. The combination of sitagliptin-metformin was well tolerated in clinical trials. The addition of sitagliptin to metformin does not appear to worsen the known gastrointestinal side effects associated with metformin monotherapy, which can often be minimized with slow uptitration of dose and administration with meals.
Although the addition of either sitagliptin or metformin to sulfonylurea therapy is associated with some degree of hypoglycemia, this complication is rarely seen with sitagliptin-metformin combination therapy. The effect of this combination on body weight is generally favorable. In clinical trials, patients receiving sitagliptin-metformin combination therapy generally maintained their weight or lost an average of up to $1.5 \mathrm{~kg}$ in weight. This is a desirable effect, particularly when compared with the weight gain generally conveyed by alternative glucose-lowering therapies, such as sulfonylureas, thiazolidinediones, or insulin. The clinical trials experienced to date suggests that patients with poorly controlled diabetes at baseline were somewhat more likely to discontinue sitagliptin-metformin due to lack of efficacy than were patients assigned to sitagliptin-sulfonylurea; otherwise, rates of drug discontinuation due to adverse events have been quite low. ${ }^{32,33}$ Overall, combination sitagliptin-metformin therapy for type 2 diabetes appears to be well tolerated and acceptable to patients.

\section{Conclusion}

Despite the availability of many different oral agents for the management of type 2 diabetes, almost half of individuals remain suboptimally controlled. The reasons for this are likely multifactorial, with some more readily remediable than others. The availability of effective and tolerable combination therapy may permit greater numbers of patients to meet therapeutic goals. Several studies have demonstrated that combinations of different classes of oral agents are more effective in glucose lowering than are maximal doses of a single drug. Furthermore, use of metformin therapy at the time of diabetes diagnosis with rapid intensification of subsequent drug therapy has been recommended by both the American Diabetes Association and the European Association for the Study of Diabetes. ${ }^{5}$ Certainly, adherence may be enhanced with prescription of a smaller number of pills which incorporate medicines of low propensity to cause either hypoglycemia or weight gain. In addition, potential reduction in medication costs with combination tablets (in which the generic medication is often provided at minimal to no additional cost) may further enhance adherence to a therapeutic regimen.

Clinical trials of sitagliptin-metformin have demonstrated decreases in $\mathrm{HbA}_{1 \mathrm{C}}$ ranging from $0.5 \%$ to $2.1 \%$, with a significantly higher proportion of subjects lowering their $\mathrm{HbA}_{1 \mathrm{C}}$ to less than 7\% compared with metformin alone. ${ }^{20,28,29,33,34}$ Furthermore, this combination is associated with a mean weight loss of $0.4-1.7 \mathrm{~kg}$, similar to that 
seen with metformin alone..$^{29,30,32-35}$ The risk of hypoglycemia with this combination ranges from $1 \%$ to $5 \%$ and is equivalent to that seen with metformin monotherapy (or exenatide-rosiglitazone-metformin) and lower than that seen with a glipizide-metformin combination. ${ }^{32}$ Although sitagliptin treatment is not expected to convey the same degree of glucose lowering or the weight loss effects seen with exenatide or liraglutide therapy, the convenience of taking a medication in pill form rather than an injection may be preferable for many patients. Furthermore, although no direct comparisons have been made in clinical trials to date, initiation of sitagliptin-metformin therapy has been shown to provide $\mathrm{HbA}_{1 \mathrm{C}}$-lowering benefits similar to those reported in trials of exenatide or liraglutide monotherapy. ${ }^{41,42}$

Sitagliptin-metformin combination therapy may have a favorable impact on beta cell function. However, long-term studies will be needed to determine if the improvement in markers of beta cell function will translate into preservation of beta cell mass or greater durability of glycemic control than that seen with more traditionally prescribed therapies. As is required of all new antihyperglycemic therapies, the long-term cardiovascular safety of sitagliptin is currently under evaluation in TECOS (Trial to Evaluate Cardiovascular Outcomes after Treatment with Sitagliptin). Inclusion of a large number of patients on the combination of sitagliptin and metformin is expected. ${ }^{43}$ Although the data available from clinical trials of sitagliptin to date have not raised concerns about the drug's cardiovascular safety, sitagliptin trials prior to TECOS were of relatively short duration, did not consistently enroll a high cardiovascular risk population, and were not designed to assess reliably the cardiovascular impact of sitagliptin use. ${ }^{44}$

In summary, sitagliptin and metformin exert a complementary glucose-lowering effect and represent a well tolerated option for patients requiring therapy for type 2 diabetes. This combination should play an important role in the current treatment algorithm for this condition.

\section{Disclosure}

Dr Green has been a member of speakers' bureaus for Merck and Takeda and has received grant support from Medtronic, Amylin, and Merck. Drs Barnard and Cox report no conflicts of interest in this work.

\section{References}

1. Centers for Disease Control and Prevention. National Diabetes Fact Sheet: General information and national estimates on diabetes in the United States, 2007. Atlanta, GA: US Department of Health and Human Services, Centers for Disease Control and Prevention; 2008.
2. World Health Organization. Diabetes fact sheet No. 312, Nov 2009. Available at: http://www.who.int/mediacentre/factsheets/fs312/en/print. html. Accessed 2010 Sep 19.

3. Stratton IM, Adler AI, Neil HA, et al. Association of glycemia with macrovascular and microvascular complications of type 2 diabetes (UKPDS 35): Prospective observational study. BMJ. 2000;321: 405-412.

4. Ong KL, Cheung BMY, Wong LYF, et al. Prevalence, treatment and control of diagnosed diabetes in the US National Health and Nutrition Examination Survey 1999-2004. Ann Epidemiol. 2008;18:222-229.

5. Nathan DM, Holman RR, Buse JB, et al. Medical management of hyperglycemia in type 2 diabetes: A consensus algorithm for the initiation and adjustment of therapy. Diabetes Care. 2009;32:193-203.

6. Turner RC, Cull CA, Frighi V, et al. Glycemic control with diet, sulfonylurea, metformin, or insulin in patients with type 2 diabetes mellitus: Progressive requirement for multiple therapies (UKPDS 49). JAMA. 1999;281:2005-2012.

7. DeFronzo RA. Pharmacologic therapy for type 2 diabetes mellitus. Ann Intern Med. 1999;131:281-303.

8. Inzucchi SE. Oral antihyperglycemic therapy for type 2 diabetes. JAMA. 2002;287:360-372.

9. Charpentier G. Oral combination therapy for type 2 diabetes. Diabetes Metab Res Rev. 2002;18:S70-S76.

10. Riddle MC. Glycemic management of type 2 diabetes: An emerging strategy with oral agents, insulins, and combinations. Endocrinol Metab Clin North Am. 2005;34:77-98.

11. American Association of Clinical Endocrinologists. Medical guidelines for clinical practice for the management of diabetes mellitus. Endocr Pract. 2007;13(S1):3-68.

12. Drucker DJ, Nauck MA. The incretin system: Glucagon-like peptide-1 receptor agonists and dipeptidyl peptidase- 4 inhibitors in type 2 diabetes. Lancet. 2006;368:1696-1706.

13. Drucker DJ. Enhancing incretin action for the treatment of type 2 diabetes. Diabetes Care. 2003;26:2929-2940.

14. Holst JJ. Therapy of type 2 diabetes mellitus based on the actions of glucagon-like peptide-1. Diabetes Metab Res Rev. 2002;18:430-441.

15. Aronoff SL, Berkowitz K, Shreiner B, et al. Glucose metabolism and regulation: Beyond insulin and glucagon. Diabetes Spectr. 2004;17:183-190.

16. Ahren B. Dipeptidyl peptidase-4 inhibitors. Diabetes Care. 2007;30: 1344-1350.

17. Herman GA, Stevens C, van Dyck K, et al. Pharmacokinetics and pharmacodynamics of sitagliptin, an inhibitor of dipeptidyl peptidase IV, in healthy subjects: Results from two randomized, double-blind, placebo-controlled studies with single oral doses. Clin Pharmacol Ther. 2005;78:675-688.

18. Herman GA, Stein PP, Thornberry NA, et al. Dipeptidyl peptidase-4 inhibitors for the treatment of type 2 diabetes: Focus on sitagliptin. Clin Pharmacol Ther. 2007;81:761-767.

19. Merck and Co, Inc. 2010. Januvia prescribing information. Available at: http://www.januvia.com/sitagliptin/januvia/hcp/januvia/about_januvia/ prescribing_information.jsp. Accessed 2010 Jun 3.

20. Goodarzi MO, Bryer-Ash M. Metformin revisited: Re-evaluation of its properties and role in the pharmacopoeia of modern antidiabetic agents. Diabetes Obes Metab. 2005;7:654-665.

21. Bailey CJ. Treating insulin resistance in type 2 diabetes with metformin and thiazolidinediones. Diabetes Obes Metab. 2005;7:675-691.

22. Mannucci E, Ognibene A, Cremasco F, et al. Effect of metformin on glucagon-like peptide 1 (GLP-1) and leptin levels in obese nondiabetic subjects. Diabetes Care. 2001;24:489-494.

23. Lenhard JM, Croom DK, Minnick DT, et al. Reduced serum dipeptidyl peptidase-IV after metformin and pioglitazone treatments. Biochem Biophys Res Comm. 2004;324:92-97.

24. Scheen AJ. Clinical pharmacokinetics of metformin. Clin Pharmacokinet. 1996;30:359-371.

25. Salpeter S, Greyber E, Pasternak G, et al. Risk of fatal and nonfatal lactic acidosis with metformin use in type 2 diabetes mellitus. Cochrane Database Syst Rev. 2006;1:CD002967. 
26. Herrington WG, Levy JB. Metformin: Effective and safe in renal disease? Int Urol Nephrol. 2008;40:411-417.

27. Migoya E, Miller J, Larson P, et al. A randomized, placebo-controlled, double-blind, double-dummy, crossover study to assess the effects of sitagliptin and metformin on post-meal incretin hormone concentrations in healthy adult subjects. Oral presentation OR-0286 at the 67th meeting of the American Diabetic Association. 2007 Jun 22-26. Chicago, IL

28. Charbonnel B, Karasik A, Liu J, Wu M, Meininger G. Efficacy and safety of the dipeptidyl peptidase-4 inhibitor sitagliptin added to ongoing metformin therapy in patients with type 2 diabetes inadequately controlled on metformin alone. Diabetes Care. 2006;29:2638-2643.

29. Goldstein BJ, Feinglos MN, Lunceford JK, Johnson J, WilliamsHerman DE; Sitagliptin 036 Study Group. Effect of initial combination therapy with sitagliptin, a dipeptidyl peptidase-4 inhibitor, and metformin on glycemic control in patients with type 2 diabetes. Diabetes Care. 2007;30:1979-1987.

30. Williams-Herman D, Johnson J, Teng R, et al. Efficacy and safety of initial combination therapy with sitagliptin and metformin in patients with type 2 diabetes: A 54-week study. Curr Med Res Opin. 2009;25:569-583.

31. Raz I, Chen Y, Wu M, et al. Efficacy and safety of sitagliptin added to ongoing metformin therapy in patients with type 2 diabetes. Curr Med Res Opin. 2008;24:537-550.

32. Nauck MA, Meininger G, Sheng D, Fanurik D, Stein PP. Efficacy and safety of the dipeptidyl peptidase-4 inhibitor, sitagliptin, compared with the sulfonylurea, glipizide, in patients with type 2 diabetes inadequately controlled on metformin alone: A randomized, double blind, non-inferiority trial. Diabetes Obes Metab. 2007;9:194-205.

33. Scott R, Loeys T, Davies MJ, Engel SS; Sitagliptin Study 801 Group. Efficacy and safety of sitagliptin when added to ongoing metformin therapy in patients with type 2 diabetes. Diabetes Obes Metab. 2008;10:959-969.

34. DeFronzo RA, Okerson T, Viswanathan P, Guan X, Holcombe JH, MacConell L. Effects of exenatide versus sitagliptin on postprandial glucose, insulin and glucagon secretion, gastric emptying, and caloric intake: A randomized, cross-over study. Curr Med Res Opin. 2008;24: 2943-2952.
35. Pratley RE, Nauck M, Bailey T, et al; 1860-LIRA-DPP-4 Study Group. Liraglutide versus sitagliptin for patients with type 2 diabetes who did not have adequate glycaemic control with metformin: A 26 week, randomized, parallel-group, open-label trial. Lancet. 2010;375:1447-1456.

36. Monami M, Iacomelli I, Marchionni N, Mannucci E. Dipeptidylpeptidase-4 inhibitors in type 2 diabetes: A meta-analysis of randomized clinical trials. Nutr Metab Cardiovasc Dis. 2010;20:224-235.

37. Richter B, Bandeira-Echtler E, Bergerhoff K, Lerch C. Dipeptidyl peptidase-4(DPP-4) inhibitors for type 2 diabetes mellitus. Cochrane Database Syst Rev. 2008;16:CD006739.

38. FDA post-marketing drug safety information. Available at: http://www. fda.gov/Drugs/DrugSafety/PostmarketDrugSafetyInformationforPa tientsandProviders/DrugSafetyInformationforHeathcareProfessionals/ ucm183764.htm. Accessed 2009 Sep 19.

39. Dore DD, Seeger JD, Arnold Chan K. Use of a claims-based active drug safety surveillance system to assess the risk of acute pancreatitis with exenatide or sitagliptin compared with metformin or glyburide. Curr Med Res Opin. 2009;25:1019-1027.

40. Goodarzi MO, Bryer-Ash M. Metformin revisited: Re-evaluation of its properties and role in the pharmacopoeia of modern antidiabetic agents. Diabetes Obes Metab. 2005;7:654-665.

41. Moretto TJ, Milton DR, Ridge TD, et al. Efficacy and tolerability of exenatide monotherapy over 24 weeks in antidiabetic drug-naive patients with type 2 diabetes: A randomized, double-blind, placebo-controlled, parallel-group study. Clin Ther. 2008;30:1448-1460.

42. Garber A, Henry R, Ratner R, et al. Liraglutide versus glimepiride monotherapy for type 2 diabetes (LEAD-3 Mono): A randomised, 52-week, phase III, double-blind, parallel-treatment trial. Lancet. 2009; 373:473-481.

43. Bethel MA, Green JB, Califf RM, Holman RR. Rationale and design of the trial evaluating cardiovascular outcomes with sitagliptin (TECOS). Diabetologia. 2009;52(S1):S480.

44. Williams-Herman D, Engel SS, Round E, et al. Safety and tolerability of sitagliptin in clinical studies: A pooled analysis of data from 10,246 patients with type 2 diabetes. BMC Endocr Disord. 2010;10:7.

\section{Publish your work in this journal}

Diabetes, Metabolic Syndrome and Obesity: Targets and Therapy is an international, peer-reviewed open-access journal committed to the rapid publication of the latest laboratory and clinical findings in the fields of diabetes, metabolic syndrome and obesity research. Original research, review, case reports, hypothesis formation, expert opinion and commentaries are all considered for publication. The manuscript management system is completely online and includes a very quick and fair peer-review system, which is all easy to use. Visit http://www.dovepress.com/testimonials.php to read real quotes from published authors. 